\title{
Electromyography of Pelvic Floor Muscles in Rats
}

\author{
Yolanda Cruz Gómez¹, Hai-Hong Jiang,3, Paul Zaszczurynski, \\ Raúl Juárez ${ }^{5}$, César Pastelin ${ }^{6}$ and Margot S. Damaser 2,3,4 \\ ${ }^{1}$ Centro Tlaxcala de Biología de la Conducta, Universidad Autónoma de Tlaxcala, Tlax. \\ ${ }^{2}$ Glickman Urological \& Kidney Institute, the Cleveland Clinic, Cleveland, $\mathrm{OH}$ \\ ${ }^{3}$ Department of Biomedical Engineering, the Cleveland Clinic, Cleveland, $\mathrm{OH}$ \\ ${ }^{4}$ Advanced Platform Technology Rehabilitation Research \& Development Center \\ Louis Stokes VA Medical Center, Cleveland, $\mathrm{OH}$ \\ ${ }^{5}$ Maestría en Ciencias Biológicas, Universidad Autónoma de Tlaxcala,Tlax. \\ ${ }^{6}$ Doctorado en Neuroetología, Universidad Veracruzana, Ver. \\ 1,5,6 México \\ $2,3,4$ USA
}

\section{Introduction}

The pelvic floor muscles (PFM) form a hammock-like structure that closes the pelvic outlet and supports the pelvic viscera to maintain their position (Ashton-Miller et al. 2001). As such, they are important for maintenance of continence, both urinary and fecal, particularly in women, since women have a smaller external urethral sphincter (EUS). Dysfunction of these muscles is clinically related to female pelvic floor disorders, a spectrum of conditions that include pelvic organ prolapse as well as both urinary and fecal incontinence (AshtonMiller \& Delancey 2009; Shafik 2000; Thor \& de Groat 2010).

Electromyography (EMG) is commonly used clinically to assess the integrity of the PFM, which include the coccygeus, iliococcygeus, and pubococcygeus (Ashton-Miller \& Delancey 2009; Thor \& de Groat 2010; Weidner et al. 2000; Weidner et al. 2000). Muscle activity is usually recorded through the anus or vagina using needle or surface electrodes during voluntary contraction of the PFM, during micturition, or during abdominal Credé maneuvers (Ashton-Miller \& Delancey 2009; Chantraine \& de 1978; Thor \& de Groat 2010; Weidner et al. 2000a; Weidner et al. 2000b). This technique assumes that the pelvic floor behaves as a single unit and EMG recordings are comparable regardless of the recording location or the methods used. However, the PFM is not a single muscle. For example, only a limited number of PFM fibers are in close anatomical relation to the urethra, and therefore are more likely to play a greater role in maintaining urinary continence. We do not know whether, independent of their position, all fibers discharge simultaneously or have differentiated responses for maintaining continence.

Rats are the animal model most commonly utilized to study the mechanisms of continence and for preclinical testing of treatments since they are readily available and, despite their quadruped status, their PFM anatomy and innervation bears a distinct similarity to humans 
(Bremer et al. 2003; Jiang et al. 2010; Poortmans \& Wyndaele 1998; Poortmans \& Wyndaele 2002; Thor \& de Groat 2010). The pelvic muscles form a bowl-shaped support attached to the pelvis, the coccyx, the pelvic ligaments and supports the vesical organs (Ashton-Miller et al. 2001; Wall 1993). Anatomic landmarks for these muscles in female rats are generally similar to those in women except for the lack of a puborectalis muscle in rats and the coccyx which controls the well-developed tail in the rat (Barber et al. 2002; Borirakchanyavat et al. 1997; Pacheco et al. 1989). In female rats the pubococcygeus and iliococcygeus are primarily innervated by the levator ani nerve from the L6-S1 trunk (Figure 1) (Bremer et al. 2003; Jiang et al. 2010)

The levator ani nerve travels into the pelvic floor from the ventromedial surface and the nerve roots are generally more proximal in female rats compared to women (Barber et al. 2002; Jiang et al. 2010). However, the course and innervation of the levator ani nerve are similar between female rats and women (Barber et al. 2002; Jiang et al. 2010). Some reports have debated if the pudendal nerve also innervates the pelvic floor muscle both in rats and women (Barber et al. 2002; Erdogru 2008; Grigorescu et al. 2008; Strohbehn 1998; Wall 1993; Wallner et al. 2008). However, most of the anatomic and functional studies support the idea that the pudendal nerve does not contribute to the innervations of these muscles (Jiang et al. 2010; Thor \& de Groat 2010).
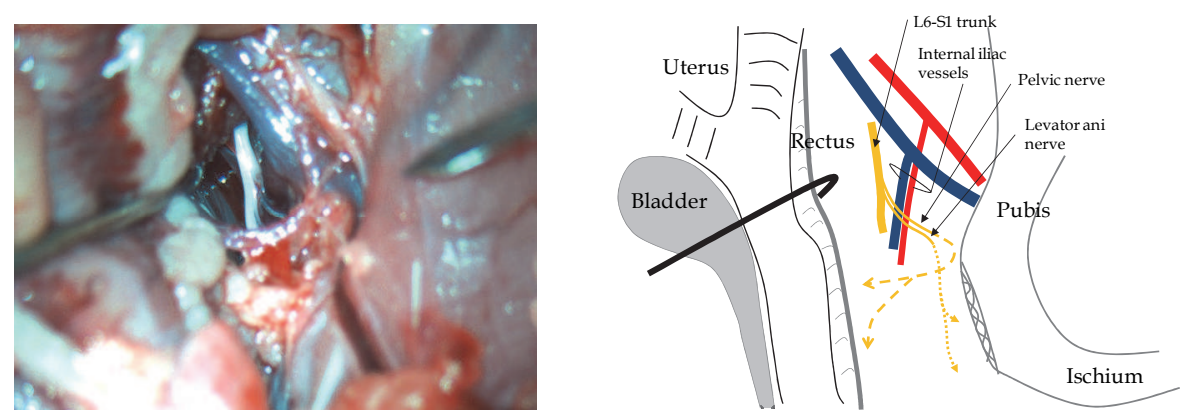

Fig. 1. Exposure of the levator ani nerve (left) in a female rat. The nerve branches from the L6-S1 trunk and enters the pelvic floor along with the pelvic nerve from its ventromedial surface.

The goal of this chapter is to review the literature regarding measurement of PFM EMGs in laboratory rats, focusing on methods and results to date and to present original data utilizing EMG measurement to determine if these muscles act as a single unit or act individually during micturition.

\section{Electrodes and techniques used to measure PFM EMGs in laboratory rats}

Several different electrodes have been utilized to study EMGs of pelvic and perineal muscles in rats, including concentric electrodes (Kerns et al. 2000), parallel electrodes (Jiang et al. 2009a, 2009b), and wire electrodes (Chang \& Havton 2008; Cruz \& Downie 2006; Peng et al. 2006; Yang et al. 2010). Several muscles in or close to the pelvic floor have been studied in rats, including the pubococcygeus, iliococcygeus, EUS, and external anal sphincter (EAS) muscles (Manzo et al. 1997; Salcedo et al. 2010; Thor \& de Groat 2010). EUS EMG in female rats has been investigated more often than EMGs of the other pelvic or perineal muscles 
because of the clinical relevance to stress incontinence and urodynamic testing (Jiang et al. 2009b; Kerns et al. 2000; Peng et al. 2006; Thor \& de Groat 2010).

\subsection{Techniques for recording EMG of pelvic floor muscles in rats}

Rats are usually anesthetized with urethane or ketamine and xylazine intraperitoneally for EMG recordings (Chang et al. 2007; Chang \& Havton 2008; Jiang et al. 2009a, 2009b; Pikov et al. 1998). Sometimes isoflurane is used to supplement anesthesia during surgical preparation for the recording (Miyazato et al. 2008). To access pelvic and perineal muscles, the pubic symphysis is exposed with the rat in a supine position and after a hypogastric midline incision. The rectus muscles are then transected and the Retzius space is exposed after opening the pubic symphysis with mosquito forceps. To avoid unexpected bleeding, the bilateral inferior epigastric vessels are ligated and cut before opening the pubic symphysis (Jiang et al. 2010). Using wire electrodes, the EUS can be approached ventromedially by inserting a 30-gauge needle (Jiang et al. 2010).

If a caudal approach is needed, the pubococcygeus and iliococcygeus muscles can be partly exposed by bluntly separating the pubic symphysis to the ischiorectal fossa. The ischiorectal fossa is then opened slightly to approach the pubococcygeus and iliococcygeus muscles. The needle can be inserted through the ischiorectal fossa to the muscles (Figure 2, blue arrow in panel A). Parallel electrodes have been used to measure pelvic floor muscle EMGs by touching the electrodes to the muscles through the muscle surface nearest the pelvis (Jiang et al. 2010). If a survival procedure for the PFM EMG is necessary, the PFM may be approached without opening the pubic symphysis or via a dorsal approach after opening the ischiorectal fossa.
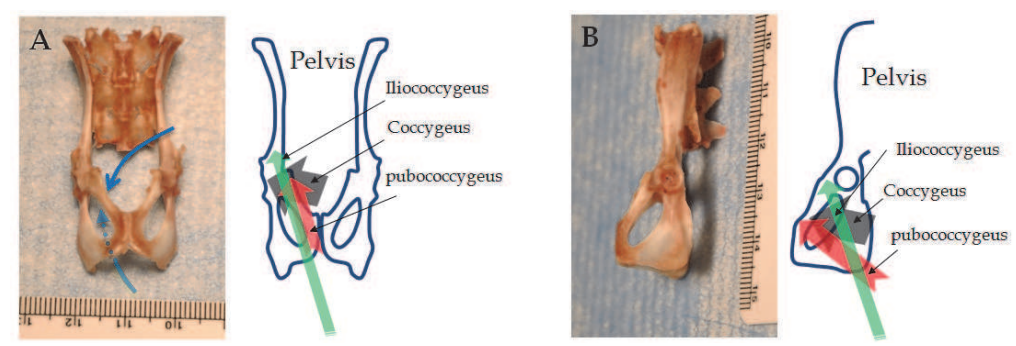

Fig. 2. Illustration of pelvic floor muscle attachments showing the direction of muscle contraction (arrows in right panels). A: vertical view of a female rat pelvis (blue arrows in left panel show the different approaches for recording pelvic floor muscles). B: lateral view of the same pelvis.

\subsection{Techniques for recording EUS EMG in rats}

EUS EMG in rats has been extensively studied for evaluation of lower urinary tract function and dysfunction (Jiang et al. 2009b; Kerns et al. 2000; Peng et al. 2006; Steward et al. 2010; Thor \& de Groat 2010). The recording is usually performed simultaneous with recording bladder pressure during cystometry (CMG) or leak point pressure (LPP) testing to test the urinary continence reflex and coordination between the bladder and urethra (Jiang et al. 2009a; Peng et al. 2006; Steward et al. 2010; Yang et al. 2010). Several approaches to the EUS using concentric electrodes, parallel electrodes, and wire electrodes have been utilized (Figure 3) (Steward et al. 2010). An end-point recording under urethane anaesthesia is one of 
most commonly used techniques to record EUS EMG (Peng et al. 2006). To obtain better quality recordings, the pubic symphysis can be bluntly separated during the procedure to enable visualization of the mid-urethra.

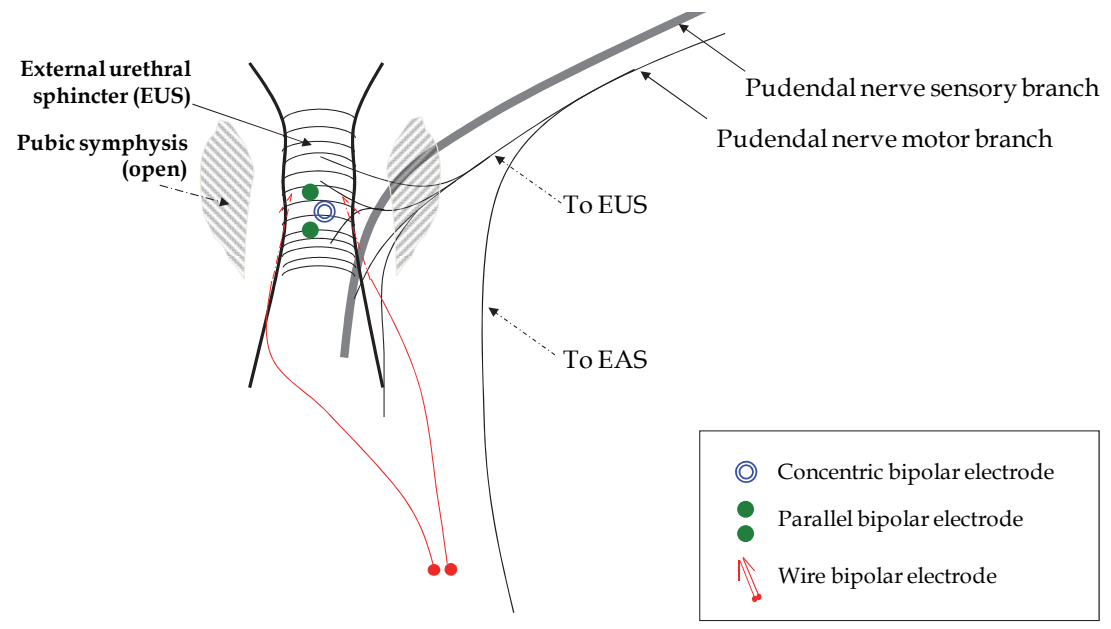

Fig. 3. Placement of different electrodes after opening the pubic symphysis for EUS EMG recording (adapted with permission from Steward et al. 2010).

If repeat EUS EMG recording is necessary, the EUS can be accessed with wire electrodes via a retropubic approach, a perineal approach, or through the anterior vaginal wall as a survival procedure under ketamine/xylazine anesthesia (Steinmetz et al. 2008). A female rat is placed in a supine position and a catheter (PE50) is inserted into the bladder via the urethral orifice to help locate the urethra for wire electrode insertion into the EUS (Figure 4). An audio monitor can be utilized to guide electrode insertion.
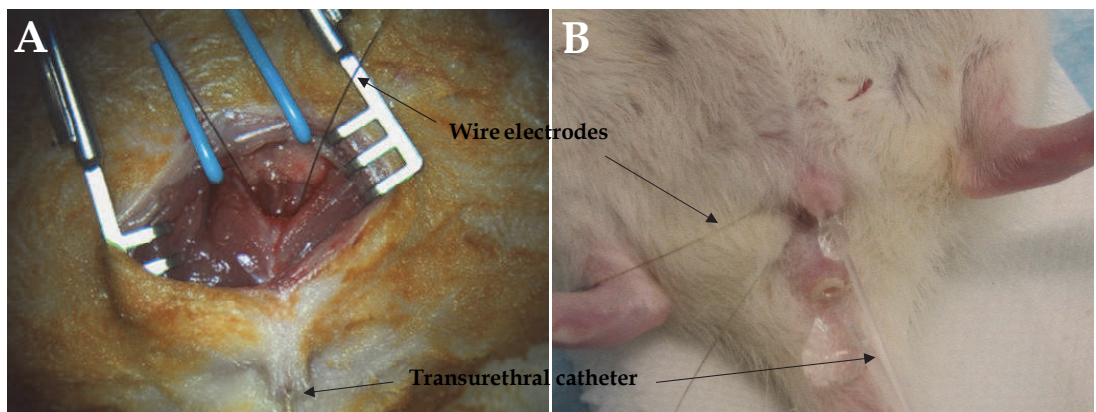

Fig. 4. Different approaches for repeat EUS EMG recording. A: retropubic approach. B: perineal or anterior vaginal wall approach.

In some animal models, such as spinal cord injury, EUS EMG may be recorded with the rat conscious but restrained. Wire electrodes are inserted via a perineal approach under isoflurane anaesthesia. Before awakening, the rats are placed in a restrainer (Figure 5) and then wakened from the anesthesia to make EMG recordings. 


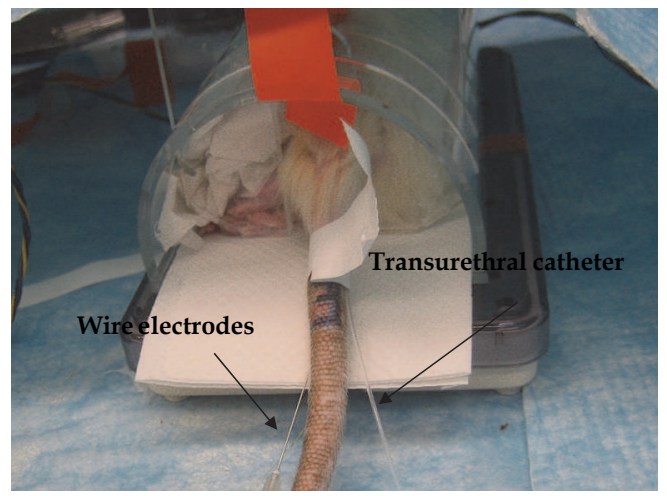

Fig. 5. A conscious spinal cord injured rat in a restrainer to make recordings of EUS EMG and bladder pressure.

\subsection{Techniques for recording the external anal sphincter EMG in rats}

EAS EMG has been well studied clinically as a substitute for EUS EMG during clinical urodynamics testing (Blaivas 1984), but is unlike the EUS EMG in rats (Salcedo et al. 2010). The anatomic location of the anus is a relatively longer distance from the urethra and vagina in rats (relative to body size) compared to women. The EAS is smaller and has reduced activity compare to the EUS in rats. In addition, the motoneurons innervating the EUS and EAS in rats are anatomically separated in the spinal cord (McKenna \& Nadelhaft 1986).

Nonetheless, EAS EMG has been studied in rats for specific purposes (Holmes et al. 1998; Salcedo et al. 2010), such as for development of an animal model of fecal incontinence (Zutshi et al. 2009). EAS EMG is recorded using a $30 \mathrm{G}$ concentric monopolar needle after inserting it into the EAS. Ketamine/xylazine anesthesia is used whether the procedure is a survival or terminal procedure, since urethane decreases anal sphincter contraction (Salcedo et al. 2010; Zutshi et al. 2009).

\section{Rat PFM EMG signal processing and analysis methods}

The majority of studies in rats involving EMG of the PFM, the EUS, or the EAS are analyzed qualitatively (Thor \& de Groat 2010). However, with the development of EMG analysis methods, quantitative analysis of the EMG has become an effective method of quantifying the continence reflex, functional recovery, and the pattern of reinnervation of these muscles (Jiang et al. 2009b; Jiang et al. 2010; Liu et al. 2008; Peng et al. 2006; Steward et al. 2010; Zutshi et al. 2009).

\subsection{EMG Signal collection and correction}

A high quality EMG signal is critical for quantitative analysis. A segmental interval is chosen, usually one to several seconds, from a stable EMG recording or at a required time point, such as at the peak of LPP testing. The segment of the EMG is then filtered for $60 \mathrm{~Hz}$ noise (power supply frequency) using a notch filter (Jiang et al. 2009a, 2009b; Steward et al. 2010). To correct for a travelling baseline in the signal, it can be smoothed using a triangular Bartlett window to obtain a signal consisting only of baseline changes (Ritter et al. 2005). This smoothed signal is then subtracted from the original signal to create a corrected signal 
(Figure 6). The resultant signal has a flattened baseline and is more appropriate for thresholding. The relative amount of baseline correction needed for each signal can be expressed as the sum of the amplitude spectrum normalized to the sum of the amplitude spectrum of the raw signal (Steward et al. 2010).

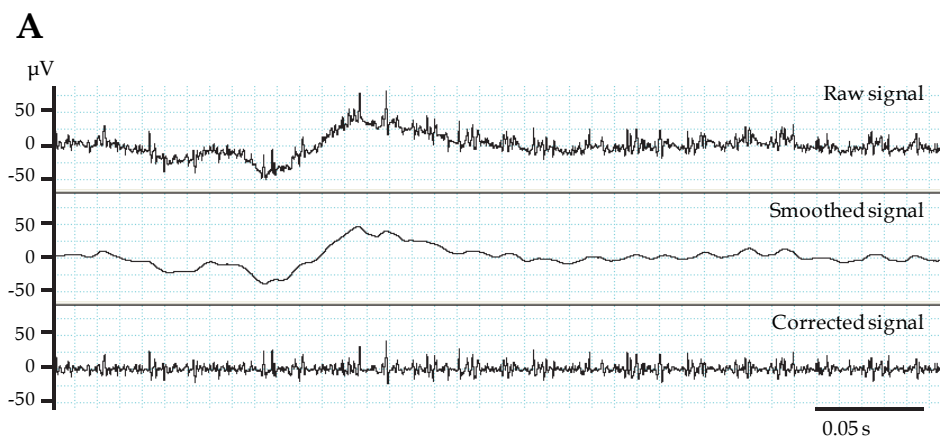

B
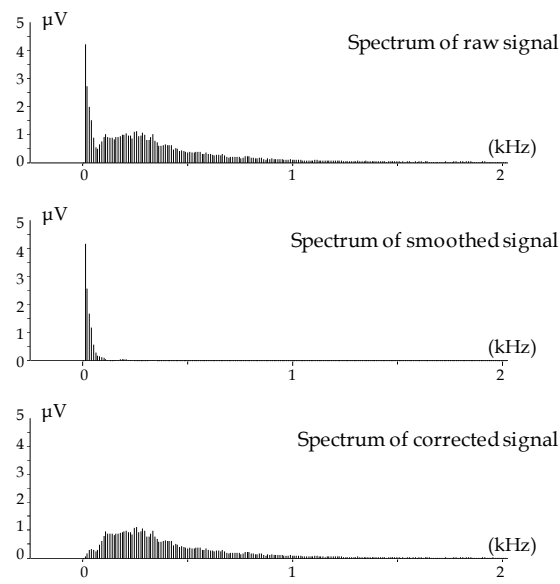

Fig. 6. Baseline correction of EMG recording. A: Example of EUS EMG during leak point pressure testing corrected by smoothing the baseline. B: Amplitude spectrums for the signal in panel A (adapted with permission from Steward et al, 2010).

\subsection{Mean amplitude and firing rate calculation}

EMG signals are then balanced by setting mean amplitude to zero to remove any offset. The signals are then rectified (Figure 7) and mean amplitude is calculated. To calculate mean firing rate of the EMG signal (previously termed "mean frequency" in Jiang et al. 2009a, 2009b; Salcedo et al. 2010; Steward et al. 2010), a threshold for differentiating noise from neuromuscular activity is set at a certain voltage (such as $0.25 \mu \mathrm{V}$ ), depending on the amplitude of noise in a particular situation. The mean firing rate is calculated by counting the number of peaks above the threshold per second (Steward et al. 2010). 


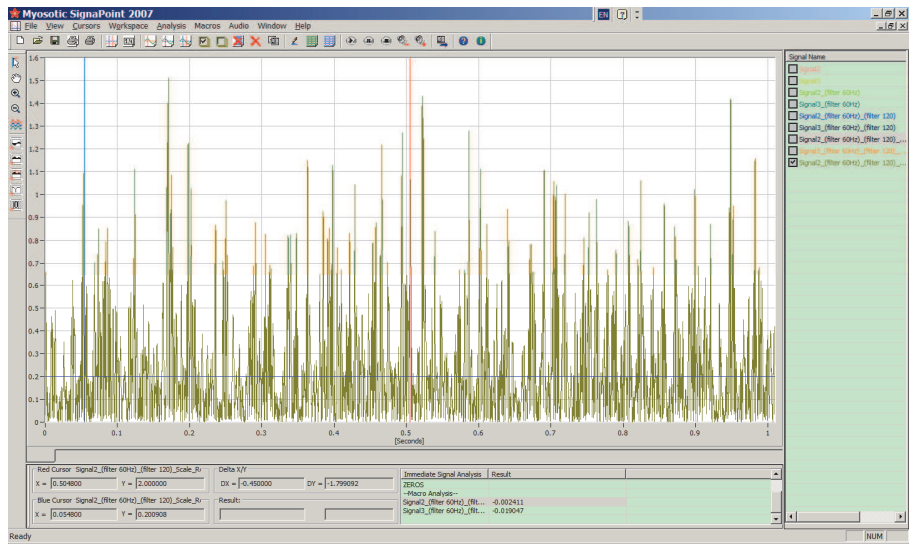

Fig. 7. Example of EMG rectification after offset. Mean amplitude and firing rate are calculated after setting a noise threshold (Myosotic SignPoint 2007).

\subsection{Individual motor unit potential (MUP) quantitative assessment}

Quantitative assessment of EMG signals can also be performed by decomposing the EMG signals to obtain individual motor unit potentials (MUPs) (Nandedkar et al. 1995; Stashuk 2001; Stålberg et al. 1996). In an example during LPP testing (Figure 8), a two-second sample of tonic baseline activity and peak activity during the pressure peak of LPP testing were identified and archived.

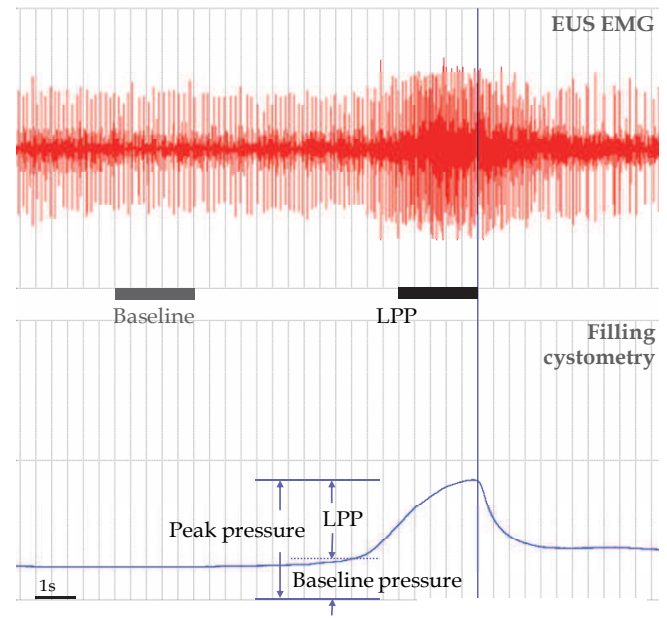

Fig. 8. Example of EUS EMG during filling CMG and LPP testing in a rat model of simulated childbirth injury, indicating recovery of continence.

Raw signals are first baseline corrected as described above. Power supply interference (60 $\mathrm{Hz}$ ) is then filtered with a digital notch filter. Each two-second sample is then decomposed using an EMG decomposition program and the averaged MUP templates are archived. The total number of MUPs and the firing rate of each MUP can be determined for each sample 
(Figure 9). Amplitude and duration of each averaged template can also be calculated, for example by using a custom Matlab code (Stålberg et al. 1996).

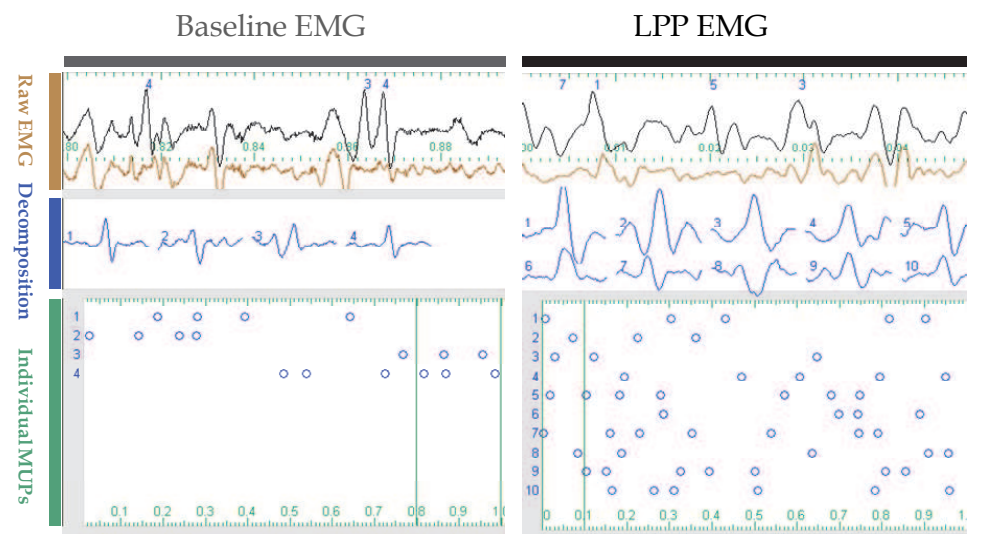

Fig. 9. EUS EMG during baseline recording and during LPP testing decomposed for individual motor unit potentials (MUPs). Increased number of MUPs in the EUS during LPP represents a guarding reflex to prevent leakage.

\section{External urethral sphincter EMG in female rats}

\subsection{Anatomy of the EUS}

The EUS, also called the rabdosphincter, consists of the striated muscle fibers surrounding the urethra (Bierinx \& Sebille 2006; RJ Kim et al. 2007; Lehtoranta et al. 2006). The fibers do not have dedicated attachments to skeletal structures and thus act as true sphincters (Cruz \& Downie 2005; RJ Kim et al. 2007; Thor \& de Groat 2010). The EUS has two peaks, one in the middle of the urethra and the other distally (RJ Kim et al. 2007).

The characteristics of the EUS are sexually dimorphic since it is thinner in females than males (Cruz \& Downie 2005). Sexual dimorphism is also observed in perineal muscles such as the bulbocavernosus and ischiocavernosus (McKenna \& Nadelhaft 1986). These muscles are well developed in males but in females are vestigial, suggesting a male sexual function (McKenna \& Nadelhaft 1986). Perineal muscles and their motoneurons degenerate after birth in females since their preservation depends on testosterone and perineal cutaneous stimulation as a neonate (Breedlove \& Arnold 1981; Moore et al. 1992; Nordeen et al. 1985). We are aware of no studies analyzing if hormonal and sensory stimuli during the neonatal window could improve development, or avoid degeneration, of the EUS in females.

\subsection{Innervation of the EUS}

EUS motoneurons are located in the dorsolateral nuclei, in L6-S1 spinal cord segments, and the axons travel through the motor branch of the sacral plexus, also called the motor branch of the pudendal nerve, to reach their target (Cruz et al. 2004; de Groat et al. 2001; Kane et al. 2002; McKenna \& Nadelhaft 1986; Pacheco et al. 1997; Schroder 1980). The motor branch of the sacral plexus (Mb in Figure 10) emerges from a loop of the nerve, the sacral plexus (SP in Figure 10). The plexus is made up of two anastomotic branches: one (ap in Figure 10) arises 
from the pudendal nerve and the other (als in Figure 10) from the lumbosacral trunk (Ls-T in Figure 10).

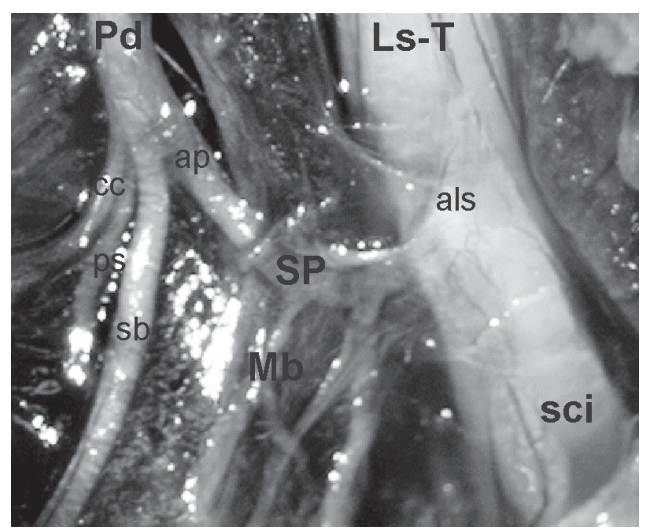

Fig. 10. Ventral view of the right sacral plexus in the female rat. Note that from the sacral plexus (SP) forms the source of innervation of the EUS (Mb, motor branch of the sacral plexus), and from the pudendal nerve (Pd), the sensory branch of the pudendal nerve (sb), and the branches to the coccygeus muscle (cc), and the perineal skin (ps). The sciatic nerve (Sci) originates from the lumbosacral trunk (Ls-T) below the sacral plexus; ap and als indicate anastomotic branches. Nerves from the sacral plexus to the perineal skin or to the internal obturator muscle are not labeled.

Knowledge of the pathways of peripheral innervation is an important tool to study EUS function in preclinical studies (Cruz \& Downie 2005; Jiang \& Damaser 2011; Jiang et al. 2009a, 2009b; Jiang et al. 2011; Kamo \& Hashimoto 2007; Kamo et al. 2009; Kamo et al. 2003; Kerns et al. 2000; Lee et al. 2003; Peng et al. 2008a, 2008b). Animal models have been used to estimate the damage to nerves during simulated childbirth and to test pharmacological and neuromodulation strategies to promote neuroregeneration and recovery of EUS function (Cannon \& Chancellor 2003; Cannon et al. 2002; Jiang \& Damaser 2011; Jiang et al. 2009a, 2009b; Peng et al. 2008a; Streng et al. 2001; Thor 2003; Thor et al. 1989; Thor et al. 2007; Vera \& Nadelhaft 2001). EMG EUS activity, or contraction, is usually measured along with bladder pressure, urethral pressure, leak point pressure and/or voiding frequency before and after a lesion to or stimulation of one or more of the nerves that innervate the EUS (Cruz \& Downie 2005; Jiang \& Damaser 2011; Jiang et al. 2009b; Peng et al. 2006; Peng et al. 2008a, $2008 b)$. However, it is difficult to compare results because some studies do not describe the site of the nerve lesion and the dissection procedures to access the nerves differ between studies (Cruz \& Downie 2005; Damaser et al. 2007; Furuta et al. 2008; Kamo et al. 2003; Kim et al. 2009; Peng et al. 2006; Wai et al. 2004).

A procedure commonly used to eliminate EUS activity is to make a lesion to the pudendal nerve. The pudendal nerve has been described as a nerve emerging from the L6-S1 trunk, the remaining one after the pelvic nerve leaves this trunk. As demonstrated in Figure 10, several branches emerge from the pudendal nerve: one provides innervation to the EUS and the others innervate the perigenital skin, the clitoris, and the coccygeus (Cruz et al. 2004; McKenna \& Nadelhaft 1989; Pacheco et al. 1997; Pacheco et al. 1989). Some authors perform pudendal nerve lesion at the level of the iliac vein, cutting all branches, others lesion the 
nerve at the ischiorectal fossa, damaging the sensory branch of the pudendal nerve and the motor branch of the sacral plexus or only the motor branch of the sacral plexus (Cruz \& Downie 2005; Damaser et al. 2007; Furuta et al. 2008; Kerns et al. 2000; Peng et al. 2006). Results of these studies are therefore not comparable.

Confusion is added with models of stress urinary incontinence created by lesioning the sciatic nerve to denervate the EUS (YT Kim et al. 2007; Kwon et al. 2006). A question arises whether the sciatic, as well as the pudendal nerve innervates the EUS. The authors probably lesioned the lumbosacral trunk (Ls-T in Figure 10). This would suggest that the axons of the EUS travel to the spinal cord through two pathways: the pudendal nerve and the lumbosacral trunk. Cutting either the pudendal nerve or the lumbosacral trunk would then not completely eliminate EUS activity. Because of this complexity of innervation, the exact site of a nerve lesion should be described in detail when presenting original studies.

\subsection{EUS EMG activity}

The activity of the EUS is related to urethral function. Simultaneous CMG and EMG recordings have shown EUS activity during high bladder pressure during effort that increases intra-abdominal pressure and during voiding (Cruz \& Downie 2005; Jiang et al. 2010). In preclinical studies these conditions are imitated by the LPP test or by infusing saline to fill the bladder and induce reflex micturition (Jiang \& Damaser 2011). LPP is associated with augmented EUS EMG activity (Jiang et al. 2010), as shown in Figure 8. This reflex muscle contraction closes the urethra to avoid urine leakage and has been recognized as a guarding reflex that relies on intact neural circuitry. Damage to nerves that innervate the EUS can weaken or eliminate the guarding reflex, decreasing urethral pressure and enabling urine leakage, similar to the clinical condition of stress urinary incontinence.

During the micturition cycle, activity of some motor units of the EUS maintains the muscular tone of the urethral sphincter during bladder filling, contributing to continence. With increasing bladder pressure, more EUS motor units are recruited and EUS EMG activity rises, one form of the guarding reflex (Jiang et al. 2010; Kenton et al. 2005; Thor \& de Groat 2010). Unlike in humans, in rats EUS discharge reaches its maximum amplitude at the peak of bladder contraction during voiding and gradually decreases after bladder pressure returns to baseline (Cruz \& Downie 2005; Streng et al. 2004; Streng et al. 2002) (Figure 11).
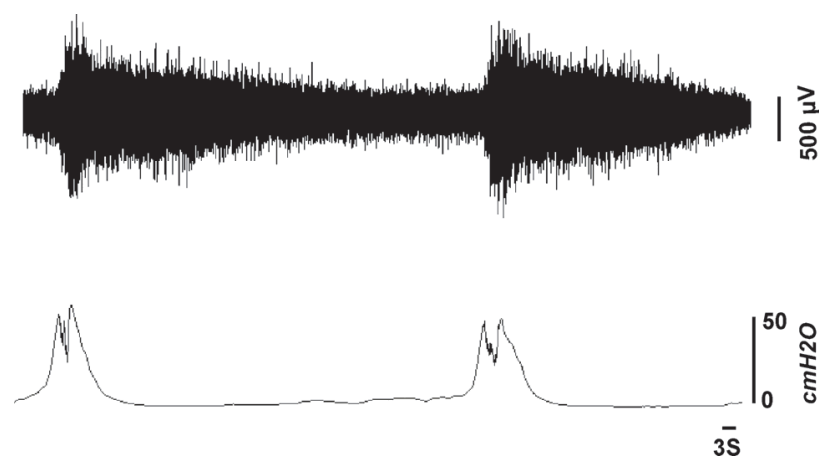

Fig. 11. EUS EMG and Bladder pressure recorded during continuous infusion of saline solution $(5 \mathrm{ml} / \mathrm{h})$. Voiding occurred between the two bladder pressure peaks. 
During voiding in rats, the highest amplitude components of EUS EMG show a 6-10 Hz bursting pattern of activity concurrent with high frequency bladder oscillations and continued as tonic activity after the bladder contraction ends (Cruz \& Downie 2005; Streng et al. 2004; Streng et al. 2002) (Figure 12A). This is in contrast to humans, in whom the EUS is quiet during voiding with little activity recorded on EMG (Yalla \& Resnick 1997). A similar pattern is observed during LPP when urine leaks but with a smaller duration than during voiding and no bursting pattern (Figure 12B).

A

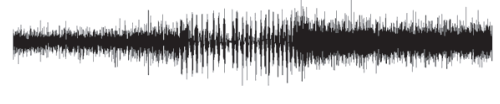

A
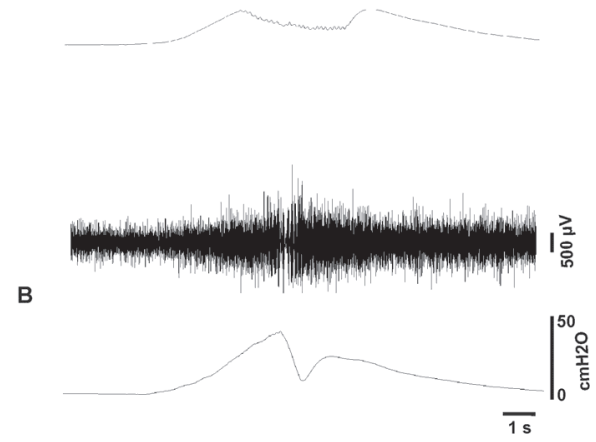

Fig. 12. EUS EMG and bladder pressure during voiding (A) and during leak point pressure testing (B). Note the bursting pattern in the EUS EMG during voiding. Scales apply to both figures.

It is not known whether the bursting pattern in EUS EMG activity results from temporally rhythmic inhibition of the EUS spinal motoneurons, since inhibition of the EUS is required for voiding in other species such as humans (Yalla \& Resnick 1997), or from recruitment of motoneurons with a bursting pattern of firing. Nonetheless, the bursting activity of the striated sphincter during voiding is necessary for efficient bladder emptying (Cruz \& Downie 2005). Voiding deficiency after spinal cord injury is correlated with decreased bursting and increased tonic activity during bladder contraction, described as bladder sphincter dyssinergia (Kruse et al. 1993).

The activity of the EUS is not only modulated by urethral and bladder afferents but also by other peripheral and central influences. In people, these reflexes mature during the first years of life since urinary continence appears postnatally. Mechanical stimulation of the genital and perineal skin increases EUS activity, suggesting that afferents from these regions also converge onto the L6-S1 segments and modulate activity of EUS motoneurons (Thor \& de Groat 2010).

\section{EMG of pelvic floor muscles in female rats}

\subsection{Coccygeal muscles in female rats}

In rats, as in humans, a group of intrapelvic striated muscles extends from the ischial spines and pubic bone to the coccygeal vertebrae. According to their individual fiber distributions, the muscles have been classified as coccygeus, iliococcygeus, iliocaudalis, pubococcygeus, or 
pubocaudalis (Brink \& Pfaff 1980; Pacheco et al. 1989; Poortmans \& Wyndaele 1998). The last two are commonly referred as the levator ani muscles, although in rats this term can be confusing because levator ani is also used to name a sexually dimorphic striated muscle closely related to the rectum that is only present in males (Cihak et al. 1970; Poortmans \& Wyndaele 1998).

The coccygeus is in a cranial-dorsal position (Cc in Figure 13) and its fibers arise from the medial face of the inominate bone, at a site just anterior to the obturator foramen. The fibers insert in the proximal tail bone, at the first and second coccygeal vertebral bone (Brink \& Pfaff 1980; Pacheco et al. 1989; Poortmans \& Wyndaele 1998). It is not directly related to the pelvic viscera.

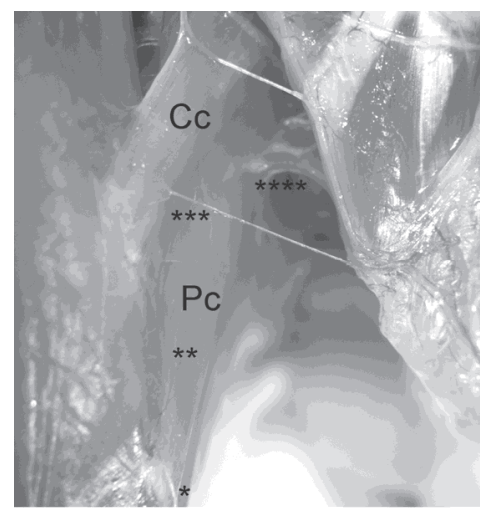

Fig. 13. Dorsal view of the pelvic floor muscles in the female rat. Cc, coccygeus muscle; Pc, pubococcygeus. Note that the iliococcygeus muscle is not observed in a dorsal view because it is ventral to the coccygeus muscle. ${ }^{*}, * *, * * *, * * * *$ indicate sites of electrode placement for EMG recordings.

The fibers of the iliococcygeus originate in the ventromedial border of the ilial shaft, posterior to the gluteal notch and insert through tendons to the coccygeal vertebrae (Poortmans \& Wyndaele 1998). The distal portions of its fibers run laterally to the rectum. The pubococcygeus is the largest muscle of the pelvic floor. Its fibers originate at the ventromedial border of the pubic bones at the level of the acetabulum and insert onto the ventromedial surface of the tail bone, at the third and fourth caudal vertebrae (Figure 13). Its ventromedial fibers have connective tissue that attach to the peritoneal surface of the ventral vaginal wall and run caudally, lateral to the rectum (Pacheco et al. 1989; Poortmans \& Wyndaele 1998). The pubococcygeus and coccygeus are closely attached and are difficult to separate from each other (Poortmans \& Wyndaele 1998).

\subsection{Innervation of pelvic floor muscles}

The motoneurons of pelvic floor muscles in rats are located in the ventral horn of the spinal cord. Tracer studies have shown that pubococcygeus motoneurons are located in a column approximately $2 \mathrm{~mm}$ in length in the central region of lamina IX of the sixth lumbar-first sacral spinal cord segments, with dendrites that project to the lateral, medial and ventral regions of the gray matter. Their morphometric characteristics are modulated by gonadal 
steroid hormones, as indicated by soma size and dendrite length and arborization reduction after ovariectomy and recovery after steroid treatment (Cuevas et al. 2006). In males it has been shown that the muscle fibers are also sensitive to gonadal steroids since castration reduces the cross-sectional area of the pubococcygeus muscle (Alvarado et al. 2008).

Afferents involved in induction of reflex activity of pelvic floor muscles travel through the pudendal and pelvic nerves (Pacheco et al. 1989). In contrast, the nomenclature for the peripheral motor innervation of the pelvic floor muscles remains controversial, with the pudendal nerve contribution to innervations of the pelvic floor muscles in question. Some studies claim that the efferent innervation of the pubococcygeus and iliococcygeus travels from the spinal cord via the somatomotor branch of the pelvic nerve, which arises from the L6-S1 trunk (Cruz et al. 2004; Pacheco et al. 1989). Others describe that these muscles are innervated by the levator ani nerve which has individual differences in the pattern of its origin (Bremer et al. 2003). In some rats the pelvic and levator ani nerves arise as distinct nerve fascicles from their origin at the L6-S1 trunk, but in most of rats (70\%), a single nerve originates from the L6-S1 trunk (usually called the pelvic nerve) and divides into the levator ani and pelvic nerves as it enters the pelvic cavity (Bremer et al. 2003). Different authors may be describing the same nerve but have named it differently (Bremer et al. 2003; Cruz et al. 2004; Pacheco et al. 1989). In recent studies (unpublished observations) we have observed that in most cases, the pelvic nerve arises as a single fascicle that divides into two branches, one carrying axons to visceral and cutaneous structures (the viscerocutaneous branch of the pelvic nerve) through the major pelvic ganglion, and the other innervating the pubococcygeus and iliococcygeus muscles. Therefore, naming it the motor branch of the pelvic nerve seems to be most appropriate (Pacheco et al. 1989).

A similar nomenclature controversy is related to innervation of the coccygeus muscle, with some authors describing the coccygeal nerve as emerging from the L6-S2 trunk, 1-2 mm distal to the point where the pelvic nerve emerges, and without contribution from the pudendal nerve (Bremer et al. 2003; Thor \& de Groat 2010). Others consider this nerve to be a branch of the pudendal nerve, as shown in Figure 10 (Cruz et al. 2004; Pacheco et al. 1989). Thus, the answer to the question of whether the pudendal nerve innervates pelvic floor muscles depends on where each investigator considers the origin of the pudendal nerve.

\subsection{EMG activity of pelvic floor muscles}

Reflex EMG activity of the iliococcygeus and pubococcygeus muscles can be induced by mechanically stimulating the perineum, clitoral sheath, or lower vagina (Martinez-Gomez et al. 1992; Pacheco et al. 1989). Contraction of this musculature, induced by electrical stimulation, produces movement of the vaginal orifice and wall, membranous urethra, tail and pelvis as well as increasing intravaginal pressure (Martinez-Gomez et al. 1992; Pacheco et al. 1989; Poortmans \& Wyndaele 1998). Thus, the pelvic floor muscles might be activated by male stimulation during copulation and could increase penile stimulation to promote ejaculation, facilitate the retention of sperm and of the seminal plug, or enhance the quality of stimulation received by the female (Martinez-Gomez et al. 1992). Contraction of these muscles may also contribute to lordotic dorsiflexion, a stereotyped posture of female rat during copulation (Brink \& Pfaff 1980; Martinez-Gomez et al. 1992).

Mechanical stimulation of the cervix inhibits the activity of pelvic floor muscles and induces reflex contraction of abdominal muscles, suggesting that the passage of the fetus through the cervix during parturition might reflexively relax the ilio- and pubococcygeus muscles, facilitating delivery (Martinez-Gomez et al. 1992; Pacheco et al. 1989). However, bilateral 
denervation of the iliococcygeus and pubococcygeus, by transection of the motor branch of the pelvic nerve, did not modify the temporal pattern of parturition (Martinez-Gomez et al. 1998). Considering that the pelvic floor muscles are inhibited during cervical stimulation, this musculature could be already inhibited during parturition such that denervation did not affect parturition.

In humans, pelvic floor muscles close the pelvic outlet and support pelvic viscera to maintain their position (Ashton-Miller \& Delancey 2007). Visceral dysfunction, such as prolapse and fecal and urinary incontinence, are related to pelvic floor muscle disorders. However, to date there are only few preclinical studies focused on EMG activity of pelvic floor muscles during excretory function (Jiang et al. 2010; Kamo et al. 2006; Kamo et al. 2009; Kamo et al. 2003). The experimental conditions and results differ between studies. In male rats, the pubococcygeus muscle shows a bursting discharge during voiding (Manzo et al. 1997). In female rats, the pubococcygeus and iliococcygeus discharge during voiding only when filling rate is high $(0.5 \mathrm{ml} / \mathrm{min})$ and they do not show bursting activity (Thor \& de Groat 2010). In contrast, in another study, the pelvic floor muscle of female rats did not demonstrate EMG activity during voiding or LPP testing (Jiang et al. 2010). Because pelvic floor muscles include several muscles, and the pubococcygeus is a large muscle, a possibility exists that this musculature does not behave as a single unit but has differential discharge. We tested this hypothesis in the following experiment.

\section{Determination of individual action of pelvic floor muscles in female rats}

\subsection{Methods}

Female virgin Sprague-Dawley rats (Harlan, Inc.) weighing 250-300 g underwent bladder filling with saline $(5 \mathrm{ml} / \mathrm{h})$ under urethane anesthesia $(1.2 \mathrm{~g} / \mathrm{kg}$, i.p.) via a suprapubic polyethelene catheter connected to both a pressure transducer and a syringe pump to monitor intravesical pressure and fill the bladder, respectively. Air pressure was calibrated as zero at the level of the bladder. On continuous saline infusion, EMGs were recorded in animals in supine $(n=5)$ or prone position $(n=3)$. In a supine position and under a microscope, a skin incision was made at the level of the pelvic bone and after cutting the pubic symphysis, the urethra was exposed. The ischium, the obturator internus muscle and the lateral perineal skin were removed to expose the pubococcygeus and iliococcygeus muscles. Care was taken to avoid cutting the perineal cutaneous innervation.

In a supine position, a pair of Teflon-coated platinum electrodes $(0.002$ in diameter, bared for $1 \mathrm{~mm}$ at the tip) were inserted in the EUS. Another pair of identical electrodes was placed in the iliococcygeus or pubococcygeus muscles. In a prone position, the skin and gluteal muscles were removed. The ischiorectal fossa was opened slightly to expose the coccygeus and pubococcygeus muscle as shown in Figure 13. The electrodes were inserted in the coccygeus or in the different sites $\left({ }^{*},{ }^{* *},{ }^{* * *},{ }^{* * *}\right)$ of the pubococcygeus muscle as indicated in Figure 13.

The electrodes were connected to an amplifier and an electrophysiological recording system to record the EMG signal $(10 \mathrm{kHz})$ simultaneous with bladder pressure recording during continuous saline infusion. In the same animal the electrodes were moved to different sites of the pelvic floor muscle. LPP testing was performed only with animals in a supine position as follows (Jiang et al. 2010). The intravesical pressure was increased by placing gentle external pressure on the bladder at approximately half bladder capacity via a cotton applicator. The external pressure was quickly withdrawn as soon as a leak was observed at 
the urethral meatus. If no EMG activity was observed during micturition, the perineal skin was mechanically stimulated to induce activity and confirm appropriate electrode position and equipment functionality.

\subsection{Results}

In a supine position neither the iliococcygeus nor any site of the pubococcygeus muscle demonstrated activity during LPP testing (Figure 14). A little EMG activity was observed during voiding when the electrodes were placed in the ventromedial fibers of the pubococcygeus muscle (Figure 14).
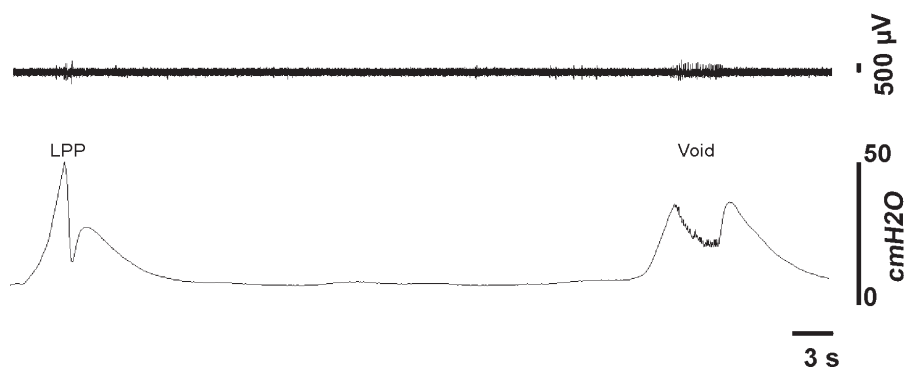

Fig. 14. EMG of the pubococcygeus muscle (upper trace) and simultaneous bladder pressure recording (bottom trace) during LPP testing and voiding in an anesthetized female rat.

Mechanical stimulation of the perigenital skin induced EMG activity of the iliococcygeus and all recording sites of the pubococcygeus muscles. The fibers of the caudal and lateral regions of the pubococcygeus demonstrated activity for the full duration of stimulus duration (Figure 15). Cutaneous stimulation failed to induce EMG activity when bladder pressure reached its maximum value and during voiding.

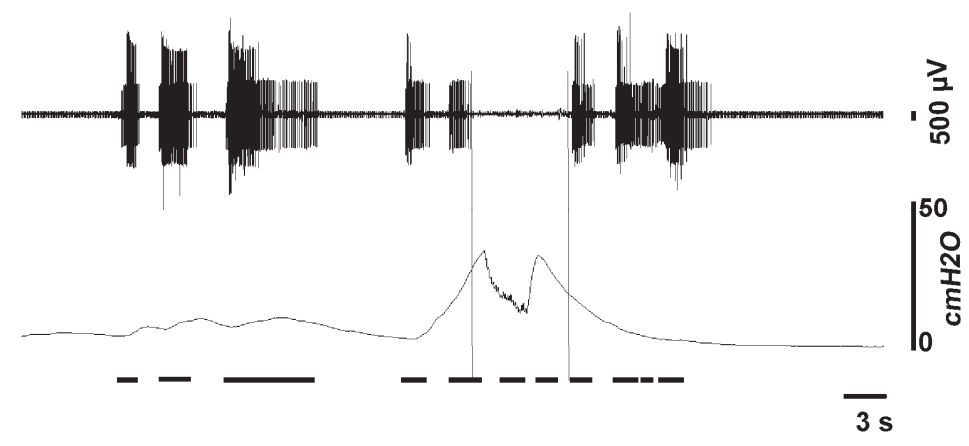

Fig. 15. EMG of the pubococcygeus muscle (upper trace) and simultaneous bladder pressure recording (bottom trace) during voiding in an anesthetized female rat. Activity of the pubococcygeus muscle was recorded close to its attachment to the coccygeal bone. Horizontal lines below the bladder pressure data indicate the duration of mechanical stimulation of the perineal skin. Note that during voiding, mechanical stimulation did not activate the pubococcygeus muscle. 
The fibers of the iliococcygeus and those in the medial region of the pubococcygeus (close to the urethra) responded to perigenital stimulation with a long afterdischarge (Figure 16). Cutaneous stimulation-induced EMG activity of the pubococcygeus was completely inhibited during LPP testing and voiding (Figure 16A and B). The inhibition started before bursting in the EUS EMG and ended when the bladder pressure decreased after voiding and the EUS showed tonic activity. However, EMG activity of the iliococcygeus was inhibited only during voiding and for a shorter period (Figure 16C).
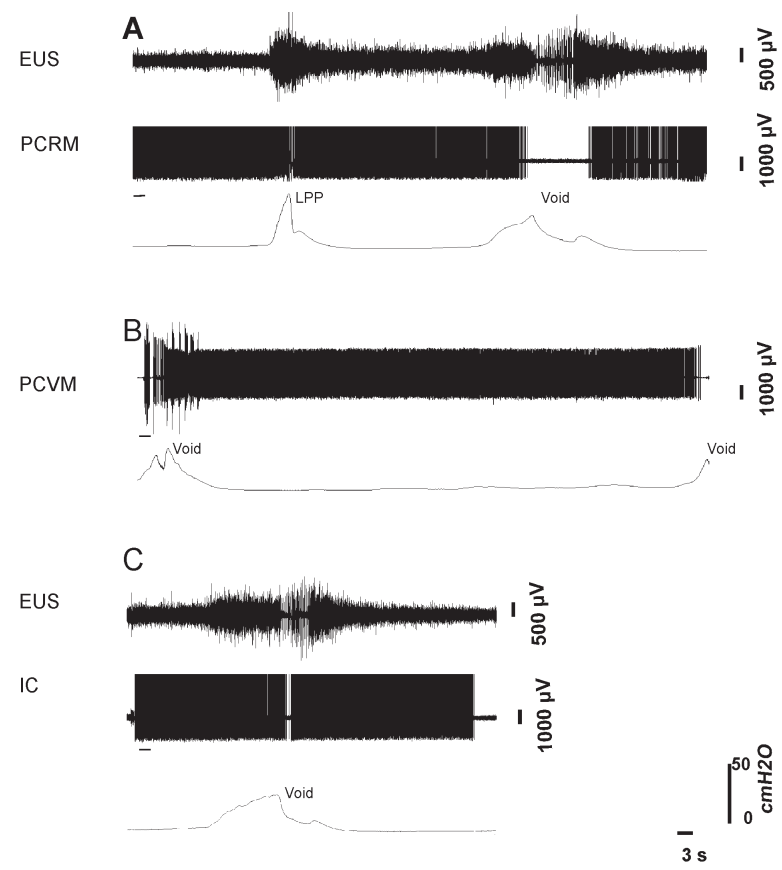

Fig. 16. EMG of the pubococcygeus muscle (middle trace in A and upper trace in B), external urethral sphincter (EUS: top trace in A \& C), and iliococcygeus (IC; middle trace in C) as well as simultaneous bladder pressure recording (bottom trace) during LPP testing and voiding in an anesthetized female rat. PCRM, rostromedial fibers of the pubococcygeus; PCVM, ventromedial fibers of the pubococcygeus. The horizontal line below EMG data indicates the duration of mechanical stimulation of the perineal skin.

The iliococcygeus and pubococcygeus muscles discharged when the tail was held contralaterally (Figure 17). The discharge stopped when the tail was placed in the midline. Since muscle spindles have been described in the pubococcygeus muscle (Alvarado et al. 2008), the activity related to tail contralateral movement may be a reflex response with muscle spindles as afferents.

In a prone position, the coccygeus muscle and most of the pubococcygeus recording sites did demonstrate activity during micturition. However, when the electrodes were placed ventromedially (**** in Figure 13) a small discharge appeared to be measurable during voiding (A in Figure 18). However, with magnification of the signal, it seems to be an artifact, probably related to urethral movements induced by EUS contraction (B in Figure 18). 

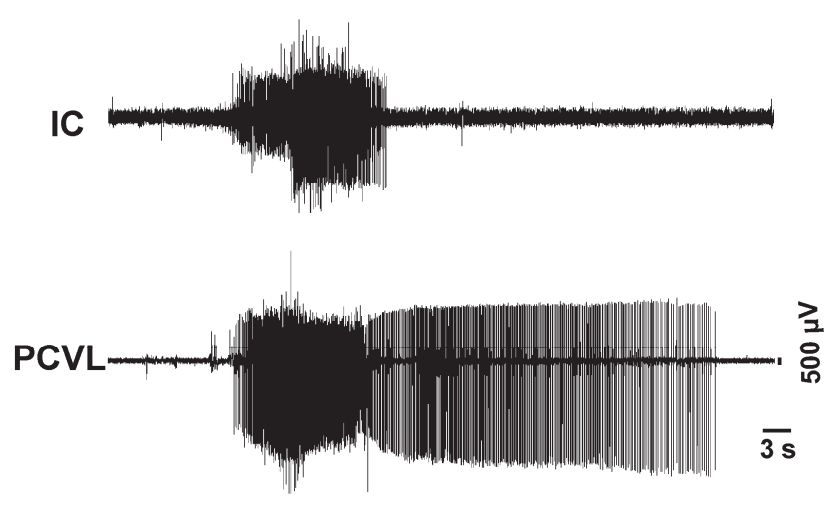

Fig. 17. EMG activity of the iliococcygeus (IC) and pubococcygeus (PCVL, ventrolateral fibers) during contralateral movement of the tail in an anesthetized female rat. The horizontal line below the EMG data indicates when the tail was held contralaterally.
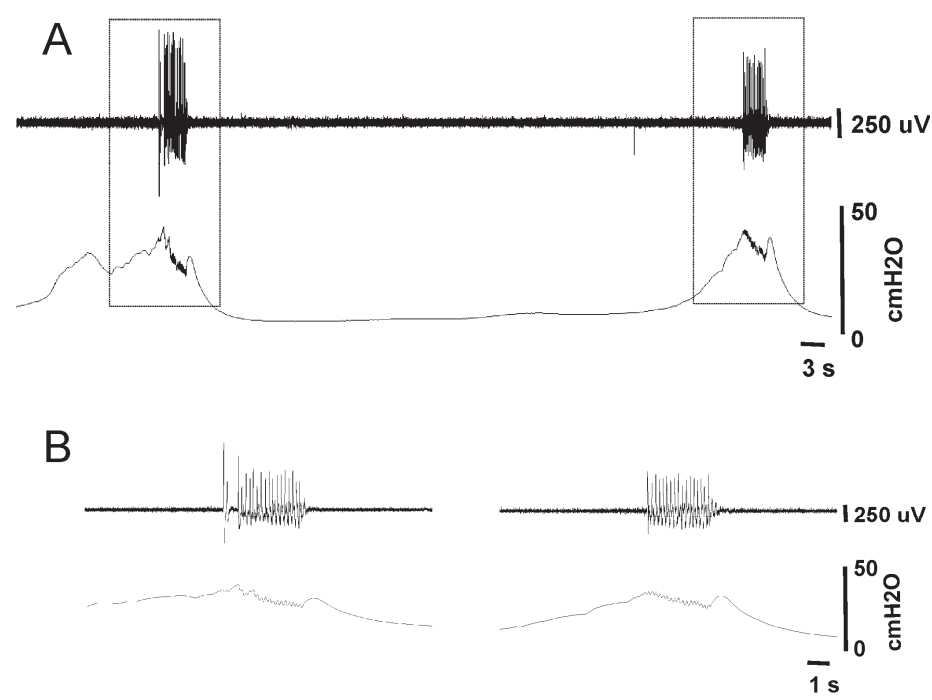

Fig. 18. EMG from the ventromedial region of the pubococcygeus muscle (upper trace) and simultaneous bladder pressure recording (bottom trace) during voiding in an anesthetized female rat. B shows the data indicated by the boxes in A on a magnified scale.

With the exception of the most distal region of the pubococcygeus (** in Figure 13), mechanical stimulation of the perigenital skin induced activity of this muscle consistently; although, in a supine position, the characteristics of the afterdischarge differed between recording sites. The dorsal fibers (*** in Figure 13) discharged only during mechanical stimulation (PCD, panel A in Figure 19) while the fibers closest to the viscera (**** in Figure 13) demonstrated an afterdischarge (PCV, panel B in Figure 19). Only some ventral fibers of the coccygeus muscle responded to perigenital stimulation with bursting potentials (CCV; Figure 19A). 
A
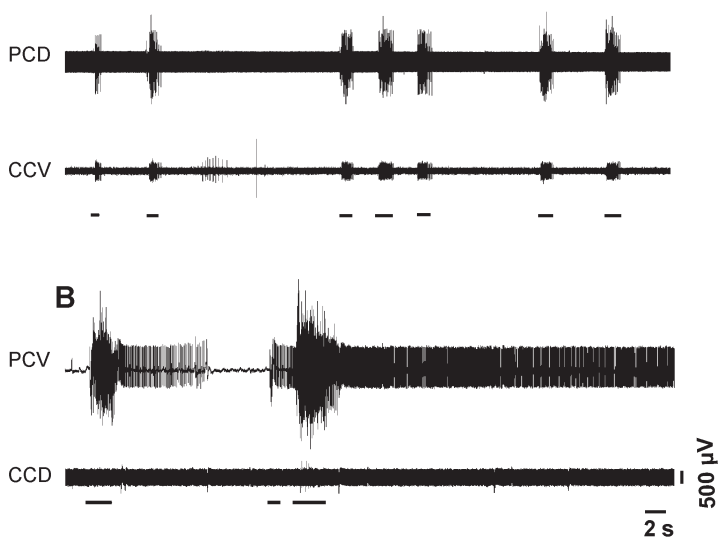

Fig. 19. Simultaneous EMG activity of the pubococcygeus and coccygeus muscle during mechanical stimulation of the perigenital skin in an anesthetized female rat. The electrodes were placed in the dorsal or ventral fibers of the pubococcygeus (PCD or PCV) or coccygeus (CCD or CCV). Horizontal lines below the EMG data indicate the duration of mechanical stimulation of the perineal skin

\section{Conclusions}

In female rats the EUS behaves as a true sphincter with anatomy and consistent reflex activity tightly linked to urethral pressure. Its responses to a suddenly increased bladder pressure represent a guarding reflex, preventing urine leakage. Its bursting potential during voiding ensures that the bladder empties efficiently (Cruz \& Downie 2005; Peng et al. 2008b; Streng et al. 2004). Its response to cutaneous and genital stimulation could increase urethral resistance to prevent voiding during intercourse.

Anatomy and activity of the pelvic floor muscles suggests that they are postural muscles primarily related to sexual function in female rats. During copulation this musculature may be activated voluntarily or reflexively by pudendal nerve afferents. However, their contribution to visceral function is not fully undertood. Their contraction seems not to be necessary for voiding, but visceral afferents seem to be inhibitory in a graded manner, depending on the muscle. We conclude that the pelvic floor musculature does not act as a single unit, neither to visceral nor to perigenital stimulation. The site of EMG recording may also influence the results. Pelvic floor inhibition during voiding suggests similarities between rats and humans in the neural control of micturition.

Some studies in rats have shown that levator ani denervation decreases urethral pressure and that neurectomized rats leak at sneeze (Conway et al. 2005; Kamo et al. 2003). However, we could not demonstrate a pelvic floor response during a LPP test and the LPP value did not decrease after levator ani nerve transection (Jiang et al 2010). It is possible that these differences stem from different experimental conditions such as pump rate and anesthesia level, which should be considered in future studies.

Clinically, measurement of the EUS and pelvic floor muscle activity is an important test to determine their integrity, innervations, and recovery from injury. However, because the muscles are intrapelvic, it is difficult to access them and the electrodes are often placed 
blindly through the vagina or anus. Alternatively, the anal sphincter is recorded as a surrogate for urethral sphincter activity (Aanestad \& Flink 1999; Chantraine \& de 1978; Kenton et al. 2005; Weidner et al. 2000; Weidner et al. 2000; Weidner et al. 2009). However, it is important to consider that the pattern of the EUS activity is different from that of pelvic floor muscles and differential responses are observed according to their topography. Recognizing the site of recording and systematically recording in comparable sites will provide consistent and comparable investigations and may avoid misdiagnoses.

\section{References}

Aanestad, O. \& Flink, R. 1999. Urinary stress incontinence. A urodynamic and quantitative electromyographic study of the perineal muscles. Acta Obstet. Gynecol. Scand., 78, 245-253.

Alvarado, M., Cuevas, E., Lara-Garcia, M., Camacho, M., Carrillo, P., Hudson, R. \& Pacheco, P. (2008). Effect of gonadal hormones on the cross-sectional area of pubococcygeus muscle fibers in male rat. Anat. Rec. (Hoboken. ), 291, 586-592.

Ashton-Miller, J.A. \& Delancey, J.O. (2007). Functional anatomy of the female pelvic floor. Ann. N. Y. Acad. Sci., 1101, 266-296.

Ashton-Miller, J.A. \& Delancey, J.O. (2009). On the biomechanics of vaginal birth and common sequelae. Annu. Rev. Biomed. Eng, 11, 163-176.

Ashton-Miller, J.A., Howard, D. \& Delancey, J.O. (2001). The functional anatomy of the female pelvic floor and stress continence control system. Scand. J. Urol. Nephrol. Suppl, 1-7.

Barber, M.D., Bremer, R.E., Thor, K.B., Dolber, P.C., Kuehl, T.J. \& Coates, K.W. (2002). Innervation of the female levator ani muscles. Am J Obstet. Gynecol., 187, 64-71.

Bierinx, A.S. \& Sebille, A. (2006). The urethral striated sphincter in adult male rat. Anatomy and Embryology, 211, 435-441.

Blaivas, J. (1984). Multichannel urodynamic studies. Urology, 23, 421.

Borirakchanyavat, S., Aboseif, S.R., Carroll, P.R., Tanagho, E.A. \& Lue, T.F. (1997). Continence mechanism of the isolated female urethra: an anatomical study of the intrapelvic somatic nerves. J Urol., 158, 822-826.

Breedlove, S.M. \& Arnold, A.P. (1981). Sexually dimorphic motor nucleus in the rat lumbar spinal cord: response to adult hormone manipulation, absence in androgeninsensitive rats. Brain Res., 225, 297-307.

Bremer, R.E., Barber, M.D., Coates, K.W., Dolber, P.C. \& Thor, K.B. (2003). Innervation of the levator ani and coccygeus muscles of the female rat. Anat. Rec. A Discov. Mol. Cell Evol. Biol., 275, 1031-1041.

Brink, E.E. \& Pfaff, D.W. (1980). Vertebral muscles of the back and tail of the albino rat (Rattus norvegicus albinus). Brain Behav. Evol., 17, 1-47.

Cannon, T.W. \& Chancellor, M.B. (2003). Pharmacotherapy for stress urinary incontinence. Rev. Urol., 5, 135-141.

Cannon, T.W., Wojcik, E.M., Ferguson, C.L., Saraga, S., Thomas, C. \& Damaser, M.S. (2002). Effects of vaginal distension on urethral anatomy and function. BJU. Int., 90, 403407.

Chang, H.Y., Cheng, C.L., Chen, J.J.J. \& de Groat, W.C. (2007). Serotonergic drugs and spinal cord transections indicate that different spinal circuits are involved in external 
urethral sphincter activity in rats. American journal of physiology. Renal physiology, 292, F1044.

Chang, H.Y. \& Havton, L.A. (2008). Differential effects of urethane and isoflurane on external urethral sphincter electromyography and cystometry in rats. Am. J. Physiol Renal Physiol, 295, F1248-F1253.

Chantraine, A. \& de, L.J. (1978). [Electromyography in usual urology (author's transl)]. J. Belge Med. Phys. Rehabil., 1, 29-34.

Cihak, R., Gutmann, E. \& Hanzlikova, V. (1970). Involution and hormone-induced persistence of the M. sphincter (levator) ani in female rats. J. Anat., 106, 93-110.

Conway, D.A., Kamo, I., Yoshimura, N., Chancellor, M.B. \& Cannon, T.W. (2005). Comparison of leak point pressure methods in an animal model of stress urinary incontinence. Int. Urogynecol. J. Pelvic. Floor. Dysfunct., 16, 359-363.

Cruz, Y. \& Downie, J.W. (2005). Sexually dimorphic micturition in rats: relationship of perineal muscle activity to voiding pattern. American Journal of Physiology-Regulatory Integrative and Comparative Physiology, 289, R1307-R1318.

Cruz, Y. \& Downie, J.W. (2006). Abdominal muscle activity during voiding in female rats with normal or irritated bladder. American journal of physiology. Regulatory, integrative and comparative physiology, 290, R1436.

Cruz, Y., Zempoalteca, R., Angelica, L.R., Pacheco, P., Hudson, R. \& Martinez-Gomez, M. (2004). Pattern of sensory innervation of the perineal skin in the female rat. Brain Res., 1024, 97-103.

Cuevas, E., Camacho, M., Alvarado, M., Hudson, R. \& Pacheco, P. (2006). Participation of estradiol and progesterone in the retrograde labeling of pubococcygeus motoneurons of the female rat. Neuroscience, 140, 1435-1442.

Damaser, M.S., Samplaski, M.K., Parikh, M., Lin, D.L., Rao, S. \& Kerns, J.M. (2007). Time course of neuroanatomical and functional recovery after bilateral pudendal nerve injury in female rats. American Journal of Physiology-Renal Physiology, 293, F1614F1621.

de Groat, W.C., Fraser, M.O., Yoshiyama, M., Smerin, S., Tai, C., Chancellor, M.B., Yoshimura, N. \& Roppolo, J.R. (2001). Neural control of the urethra. Scand. J. Urol. Nephrol. Suppl, 35-43.

Erdogru, T. (2008). Editorial comment on: the contribution of the levator ani nerve and the pudendal nerve to the innervation of the levator ani muscles: a study in human fetuses. Eur. Urol., 54, 1143-1144.

Furuta, A., Jankowski, R.J., Pruchnic, R., Egawa, S., Yoshimura, N. \& Chancellor, M.B. (2008). Physiological effects of human muscle-derived stem cell implantation on urethral smooth muscle function. Int. Urogynecol. J. Pelvic. Floor. Dysfunct., 19, 12291234.

Grigorescu, B.A., Lazarou, G., Olson, T.R., Downie, S.A., Powers, K., Greston, W.M. \& Mikhail, M.S. (2008). Innervation of the levator ani muscles: description of the nerve branches to the pubococcygeus, iliococcygeus, and puborectalis muscles. Int. Urogynecol. J. Pelvic. Floor. Dysfunct., 19, 107-116.

Holmes, G.M., Rogers, R.C., Bresnahan, J.C. \& Beattie, M.S. (1998). External anal sphincter hyperreflexia following spinal transection in the rat. Journal of neurotrauma, 15, 451.

Jiang, H.H. \& Damaser, M.S. (2011). Animal models of stress urinary incontinence. Handb. Exp. Pharmacol., 45-67. 
Jiang, H.H., Gustilo-Ashby, A.M., Salcedo, L.B., Pan, H.Q., Sypert, D.F., Butler, R.S. \& Damaser, M.S. (2009a). Electrophysiological function during voiding after simulated childbirth injuries. Exp. Neurol., 215, 342-348.

Jiang, H.H., Pan, H.Q., Gustilo-Ashby, M.A., Gill, B., Glaab, J., Zaszczurynski, P. \& Damaser, M. (2009b). Dual simulated childbirth injuries result in slowed recovery of pudendal nerve and urethral function. Neurourol. Urodyn., 28, 229-235.

Jiang, H.H., Salcedo, L.B. \& Damaser, M.S. (2011). Quantification of neurological and other contributors to continence in female rats. Brain Res., 1382, 198-205.

Jiang, H.H., Salcedo, L.B., Song, B. \& Damaser, M.S. (2010). Pelvic floor muscles and the external urethral sphincter have different responses to applied bladder pressure during continence. Urology, 75, 1515-1517.

Kamo, I. \& Hashimoto, T. (2007). Involvement of reflex urethral closure mechanisms in urethral resistance under momentary stress condition induced by electrical stimulation of rat abdomen. Am. J. Physiol Renal Physiol, 293, F920-F926.

Kamo, I., Kaiho, Y., Canon, T.W., Chancellor, M.B., de Groat, W.C., Prantil, R.L., Vorp, D.A. \& Yoshimura, N. (2006). Functional analysis of active urethral closure mechanisms under sneeze induced stress condition in a rat model of birth trauma. J. Urol., 176, 2711-2715.

Kamo, I., Kaiho, Y., Miyazato, M., Torimoto, K. \& Yoshimura, N. (2009). Two kinds of urinary continence reflexes during abrupt elevation of intravesical pressure in rats. Low Urin. Tract. Symptoms., 1, S40-S43.

Kamo, I., Torimoto, K., Chancellor, M.B., de Groat, W.C. \& Yoshimura, N. (2003). Urethral closure mechanisms under sneeze-induced stress condition in rats: a new animal model for evaluation of stress urinary incontinence. Am. J. Physiol Regul. Integr. Comp Physiol, 285, R356-R365.

Kane, D.D., Shott, S., Hughes, W.F. \& Kerns, J.M. (2002). Motor pudendal nerve characterization in the female rat. Anat. Rec., 266, 21-29.

Kenton, K., Fitzgerald, M.P. \& Brubaker, L. (2005). Striated urethral sphincter activity does not alter urethral pressure during filling cystometry. Am. J. Obstet. Gynecol., 192, 5559.

Kerns, J.M., Damaser, M.S., Kane, J.M., Sakamoto, K., Benson, J.T., Shott, S. \& Brubaker, L. (2000). Effects of pudendal nerve injury in the female rat. Neurourol. Urodyn., 19, 5369.

Kim, D.K., Jankowski, R.J., Pruchnic, R., de, M.F., Yoshimura, N., Honda, M., Furuta, A. \& Chancellor, M.B. (2009). In vitro and in vivo effect of lidocaine on rat musclederived cells for treatment of stress urinary incontinence. Urology, 73, 437-441.

Kim, R.J., Kerns, J.M., Liu, S., Nagel, T., Zaszczurynski, P., Lin, D.L. \& Damaser, M.S. (2007). Striated muscle and nerve fascicle distribution in the female rat urethral sphincter. Anat. Rec. (Hoboken. ), 290, 145-154.

Kim, Y.T., Kim, D.K., Jankowski, R.J., Pruchnic, R., Usiene, I., de, M.F. \& Chancellor, M.B. (2007). Human muscle-derived cell injection in a rat model of stress urinary incontinence. Muscle Nerve, 36, 391-393.

Kruse, M.N., Belton, A.L. \& de Groat, W.C. (1993). Changes in bladder and external urethral sphincter function after spinal cord injury in the rat. Am. J. Physiol, 264, R1157R1163. 
Kwon, D., Kim, Y., Pruchnic, R., Jankowski, R., Usiene, I., de, M.F., Huard, J. \& Chancellor, M.B. (2006). Periurethral cellular injection: comparison of muscle-derived progenitor cells and fibroblasts with regard to efficacy and tissue contractility in an animal model of stress urinary incontinence. Urology, 68, 449-454.

Lee, J.Y., Cannon, T.W., Pruchnic, R., Fraser, M.O., Huard, J. \& Chancellor, M.B. (2003). The effects of periurethral muscle-derived stem cell injection on leak point pressure in a rat model of stress urinary incontinence. Int. Urogynecol. J. Pelvic. Floor. Dysfunct., 14, 31-37.

Lehtoranta, M., Streng, T., Yatkin, E., Paranko, J., Kolts, I., Talo, A. \& Santti, R. (2006). Division of the male rat rhabdosphincter into structurally and functionally differentiated parts. Anat. Rec. A Discov. Mol. Cell Evol. Biol., 288, 536-542.

Liu, G., Lin, Y.H., Yamada, Y. \& Daneshgari, F. (2008). External urethral sphincter activity in diabetic rats. Neurourol. Urodyn., 27, 429-434.

Manzo, J., Esquivel, A., Hernandez, M.E., Carrillo, P., Martinez-Gomez, M. \& Pacheco, P. (1997). The role of pubococcygeus muscle in urinary continence in the male rat. J. Urol., 157, 2402-2406.

Martinez-Gomez, M., Chirino, R., Beyer, C., Komisaruk, B.R. \& Pacheco, P. (1992). Visceral and postural reflexes evoked by genital stimulation in urethane-anesthetized female rats. Brain Res., 575, 279-284.

Martinez-Gomez, M., Cruz, Y., Pacheco, P., Aguilar-Roblero, R. \& Hudson, R. (1998). The sensory but not muscular pelvic nerve branch is necessary for parturition in the rat. Physiol Behav., 63, 929-932.

McKenna, K.E. \& Nadelhaft, I. (1986). The organization of the pudendal nerve in the male and female rat. J. Comp Neurol., 248, 532-549.

McKenna, K.E. \& Nadelhaft, I. (1989). The pudendo-pudendal reflex in male and female rats. J. Auton. Nerv. Syst., 27, 67-77.

Miyazato, M., Sasatomi, K., Hiragata, S., Sugaya, K., Chancellor, M.B., de Groat, W.C. \& Yoshimura, N. (2008). GABA receptor activation in the lumbosacral spinal cord decreases detrusor overactivity in spinal cord injured rats. The Journal of urology, $179,1178$.

Moore, C.L., Dou, H. \& Juraska, J.M. (1992). Maternal stimulation affects the number of motor neurons in a sexually dimorphic nucleus of the lumbar spinal cord. Brain Res., 572, 52-56.

Nandedkar, S.D., Barkhaus, P.E. \& Charles, A. (1995). Multi-motor unit action potential analysis (MMA). Muscle E nerve, 18, 1155.

Nordeen, E.J., Nordeen, K.W., Sengelaub, D.R. \& Arnold, A.P. (1985). Androgens prevent normally occurring cell death in a sexually dimorphic spinal nucleus. Science, 229, 671-673.

Pacheco, P., Camacho, M.A., Garcia, L.I., Hernandez, M.E., Carrillo, P. \& Manzo, J. (1997). Electrophysiological evidence for the nomenclature of the pudendal nerve and sacral plexus in the male rat. Brain Res., 763, 202-208.

Pacheco, P., Martinez-Gomez, M., Whipple, B., Beyer, C. \& Komisaruk, B.R. (1989). Somatomotor components of the pelvic and pudendal nerves of the female rat. Brain Res., 490, 85-94. 
Peng, C.W., Chen, J.J., Chang, H.Y., de Groat, W.C. \& Cheng, C.L. (2006). External urethral sphincter activity in a rat model of pudendal nerve injury. Neurourol. Urodyn., 25, 388-396.

Peng, C.W., Chen, J.J., Cheng, C.L. \& Grill, W.M. (2008a). Improved bladder emptying in urinary retention by electrical stimulation of pudendal afferents. J. Neural Eng, 5, 144-154.

Peng, C.W., Chen, J.J., Cheng, C.L. \& Grill, W.M. (2008b). Role of pudendal afferents in voiding efficiency in the rat. Am. J. Physiol Regul. Integr. Comp Physiol, 294, R660R672.

Pikov, V., Gillis, R.A., Jasmin, L. \& Wrathall, J.R. (1998). Assessment of lower urinary tract functional deficit in rats with contusive spinal cord injury. Journal of neurotrauma, 15,375 .

Poortmans, A. \& Wyndaele, J.J. (1998). M. levator ani in the rat: does it really lift the anus? Anat. Rec., 251, 20-27.

Poortmans, A. \& Wyndaele, J.J. (2002). Preventing fatigue of fast striated muscles of the pelvic floor and slow striated muscles of the limb by manipulating the on-off time of electric stimulation. Arch. Phys. Med. Rehabil., 83, 550-554.

Ritter, A.B., Reisman, S. \& Michniak, B.B. (2005). Signal Acquisition and Processing. In: Biomedical Engineering Principles, pp. 265-289. CRC Press.

Salcedo, L., Damaser, M., Butler, R., Jiang, H.H., Hull, T. \& Zutshi, M. (2010). Long-term effects on pressure and electromyography in a rat model of anal sphincter injury. Dis. Colon Rectum, 53, 1209-1217.

Schroder, H.D. (1980). Organization of the motoneurons innervating the pelvic muscles of the male rat. J. Comp Neurol., 192, 567-587.

Shafik, A. (2000). The role of the levator ani muscle in evacuation, sexual performance and pelvic floor disorders. Int. Urogynecol. J. Pelvic. Floor. Dysfunct., 11, 361-376.

Stashuk, D. (2001). EMG signal decomposition: how can it be accomplished and used? Journal of electromyography and kinesiology: official journal of the International Society of Electrophysiological Kinesiology, 11, 151.

Steinmetz, M.P., Alilain, W., Horn, K., Jiang, H.H., Fletter, P., Damaser, M.S. \& Silver, J. (2008). Light induced alteration of external urethral function through the activation of channelrodopsin-2. Poster; Washington. Society for Neuroscience. 2008. Society for Neuroscience 469.14/MM19..

Steward, J.E., Clemons, J.D., Zaszczurynski, P.J., Butler, R.S., Damaser, M.S. \& Jiang, H.H. (2010). Quantitative evaluation of electrodes for external urethral sphincter electromyography during bladder-to-urethral guarding reflex. World journal of urology, 28, 365.

Streng, T., Launonen, A., Salmi, S., Saarinen, N., Talo, A., Makela, S. \& Santti, R. (2001). Nontraumatic urethral dyssynergia in neonatally estrogenized male rats. J. Urol., 165, 1305-1309.

Streng, T., Santti, R., Andersson, K.E. \& Talo, A. (2004). The role of the rhabdosphincter in female rat voiding. BJU. Int., 94, 138-142.

Streng, T., Santti, R. \& Talo, A. (2002). Similarities and differences in female and male rat voiding. Neurourol. Urodyn., 21, 136-141.

Strohbehn, K. (1998). Normal pelvic floor anatomy. Obstet. Gynecol. Clin. North Am, 25, 683705 . 
Stålberg, E., Nandedkar, S.D., Sanders, D.B. \& Falck, B. (1996). Quantitative motor unit potential analysis. Journal of clinical neurophysiology: official publication of the American Electroencephalographic Society, 13, 401.

Thor, K.B. (2003). Serotonin and norepinephrine involvement in efferent pathways to the urethral rhabdosphincter: implications for treating stress urinary incontinence. Urology, 62, 3-9.

Thor, K.B. \& de Groat, W.C. (2010). Neural control of the female urethral and anal rhabdosphincters and pelvic floor muscles. Am. J. Physiol Regul. Integr. Comp Physiol, 299, R416-R438.

Thor, K.B., Hisamitsu, T., Roppolo, J.R., Tuttle, P., Nagel, J. \& Degroat, W.C. (1989). Selective inhibitory effects of ethylketocyclazocine on reflex pathways to the external urethral sphincter of the cat. J. Pharmacol. Exp. Ther., 248, 1018-1025.

Thor, K.B., Kirby, M. \& Viktrup, L. (2007). Serotonin and noradrenaline involvement in urinary incontinence, depression and pain: scientific basis for overlapping clinical efficacy from a single drug, duloxetine. Int. J. Clin. Pract., 61, 1349-1355.

Vera, P.L. \& Nadelhaft, I. (2001). Effects of the atypical neuroleptic clozapine on micturition parameters in anesthetized rats. Neurourol. Urodyn., 20, 623-639.

Wai, C.Y., Liehr, P., Boreham, M.K., Schaffer, J.I. \& Word, R.A. (2004). Effect of periurethral denervation on smooth muscles of the lower urinary tract. Am. J. Obstet. Gynecol., 191, 1950-1960.

Wall, L.L. (1993). The muscles of the pelvic floor. Clin. Obstet. Gynecol., 36, 910-925.

Wallner, C., van, W.J., Maas, C.P., Dabhoiwala, N.F., DeRuiter, M.C. \& Lamers, W.H. (2008). The contribution of the levator ani nerve and the pudendal nerve to the innervation of the levator ani muscles; a study in human fetuses. Eur. Urol., 54, 1136-1142.

Weidner, A.C., Barber, M.D., Visco, A.G., Bump, R.C. \& Sanders, D.B. (2000a). Pelvic muscle electromyography of levator ani and external anal sphincter in nulliparous women and women with pelvic floor dysfunction. Am. J. Obstet. Gynecol., 183, 1390-1399.

Weidner, A.C., Sanders, D.B., Nandedkar, S.D. \& Bump, R.C. (2000b). Quantitative electromyographic analysis of levator ani and external anal sphincter muscles of nulliparous women. Am. J. Obstet. Gynecol., 183, 1249-1256.

Weidner, A.C., South, M.M., Sanders, D.B. \& Stinnett, S.S. (2009). Change in urethral sphincter neuromuscular function during pregnancy persists after delivery. Am. J. Obstet. Gynecol., 201, 529-6.

Yalla, S.V. \& Resnick, N.M. (1997). Initiation of voiding in humans: the nature and temporal relationship of urethral sphincter responses. J. Urol., 157, 590-595.

Yang, Z., Dolber, P.C. \& Fraser, M.O. (2010). Differential vulnerabilities of urethral afferents in diabetes and discovery of a novel urethra-to-urethra reflex. Am. J. Physiol Renal Physiol, 298, F118-F124.

Zutshi, M., Salcedo, L.B., Zaszczurynski, P.J., Hull, T.L., Butler, R.S. \& Damaser, M.S. (2009). Effects of sphincterotomy and pudendal nerve transection on the anal sphincter in a rat model. Dis. Colon Rectum, 52, 1321-1329. 


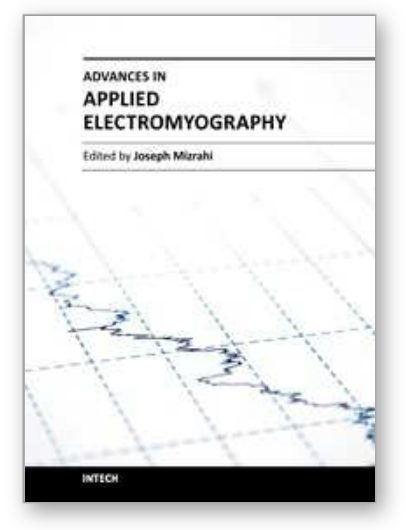

\author{
Advances in Applied Electromyography \\ Edited by Prof. Joseph Mizrahi
}

ISBN 978-953-307-382-8

Hard cover, 212 pages

Publisher InTech

Published online 29, August, 2011

Published in print edition August, 2011

The electrical activity of the muscles, as measured by means of electromyography (EMG), is a major expression of muscle contraction. This book aims at providing an updated overview of the recent developments in electromyography from diverse aspects and various applications in clinical and experimental research. It consists of ten chapters arranged in four sections. The first section deals with EMG signals from skeletal muscles and their significance in assessing biomechanical and physiologic function and in applications in neuro-musculo-skeletal rehabilitation. The second section addresses methodologies for the treatment of the signal itself: noise removal and pattern recognition for the activation of artificial limbs. The third section deals with utilizing the EMG signals for inferring on the mechanical action of the muscle, such as force, e.g., pinching force in humans or sucking pressure in the cibarial pump during feeding of the hematophagous hemiptera insect. The fourth and last section deals with the clinical role of electromyograms in studying the pelvic floor muscle function.

\title{
How to reference
}

In order to correctly reference this scholarly work, feel free to copy and paste the following:

Yolanda Cruz Gómez, Hai-Hong Jiang, Paul Zaszczurynski, Raúl Juárez, César Pastelin and Margot S. Damaser (2011). Electromyography of Pelvic Floor Muscles in Rats, Advances in Applied Electromyography, Prof. Joseph Mizrahi (Ed.), ISBN: 978-953-307-382-8, InTech, Available from:

http://www.intechopen.com/books/advances-in-applied-electromyography/electromyography-of-pelvic-floormuscles-in-rats

\section{INTECH}

open science | open minds

\section{InTech Europe}

University Campus STeP Ri

Slavka Krautzeka 83/A

51000 Rijeka, Croatia

Phone: +385 (51) 770447

Fax: +385 (51) 686166

www.intechopen.com

\section{InTech China}

Unit 405, Office Block, Hotel Equatorial Shanghai

No.65, Yan An Road (West), Shanghai, 200040, China 中国上海市延安西路65号上海国际贵都大饭店办公楼 405 单元

Phone: +86-21-62489820

Fax: +86-21-62489821 
(C) 2011 The Author(s). Licensee IntechOpen. This chapter is distributed under the terms of the Creative Commons Attribution-NonCommercialShareAlike-3.0 License, which permits use, distribution and reproduction for non-commercial purposes, provided the original is properly cited and derivative works building on this content are distributed under the same license. 